\title{
The Preauricular Sinus: A Novel Approach for Complete Bilateral Excision via a Modified Face-Lift Incision*
}

\author{
Florian M. Lampert", Georgios Koulaxouzidis, G. Björn Stark
}

Department of Plastic Surgery, University of Freiburg Medical Center, Freiburg, Germany.

Email: "\#lorian.lampert@uniklinik-freiburg.de, georgios.koulaxouzidis@uniklinik-freiburg.de, bjoern.stark@uniklinik-freiburg.de

Received January $11^{\text {th }}, 2013$; revised February $15^{\text {th }}, 2013$; accepted February $24^{\text {th }}, 2013$

Copyright (c) 2013 Florian M. Lampert et al. This is an open access article distributed under the Creative Commons Attribution License, which permits unrestricted use, distribution, and reproduction in any medium, provided the original work is properly cited.

\begin{abstract}
Objectives/Hypothesis: To present a novel technique based on the combination of aesthetic and reconstructive techniques for the radical and safe excision of preauricular sinus along with minimal cosmetic impairing. Study Design: Case report, description of surgical method and brief overview of the literature. Methods: In a patient with bilateral preauricular sinus, we used a modified face-lift incision and SMAS-fixation instead of solely excising the sinus with skin ellipse. Results: Total removal of the bilateral fistulous systems could be achieved, along with a very aesthetically pleasing result. Conclusions: The surgical approach shown here allows a radical excision with only minimal aesthetic impairment using a shortened facelift-incision and SMAS-fixation.
\end{abstract}

Keywords: Preauricular Cyst; Preauricular Sinus; Face Lift Incision; SMAS Fixation; Aesthetic Reconstructive Surgery

\section{Introduction}

Using the example of a 28 years old male patient with a long-lasting history of repetitive Infections of bilateral preauricular sinuses, we describe a refinement of the operation technique for the excision of this pathology. Instead of employing the standard operating technique, which consists of an excision limited to the cyst along with a skin spindle; we promote using a shortened pretragal facelift incision. This approach provides an excellent exposure of the operation site as a prerequisite for complete removal of the affected tissue along with an optimal cosmetic result of the inconspicuously placed scar. The procedure can be carried out under local anaesthesia. These characteristics could contribute to an optimized treatment of preauricular sinuses with further reduction of the rate of recurrence.

\section{Case Report}

A 28 years old male patient presented to us with a history of repetitive painful swelling, redness and sebaceous and purulent discharge from multiple bilateral preauricular fistulae orifices from the level of the lobule up to the crus of the helix (Figure 1) along with an oily skin type.

\footnotetext{
*The authors have no funding, financial relationships, or conflicts of interest to disclose.

" Corresponding author.
}

Apart from a previous pretragal incision and drainage of an acute abscess on the more severly affected left side several years ago, that had not led to any melioration of the symptoms, patient history did not reveal any remarkable occurrences. In particular, no other lesions of this kind in further locations were found, also no alterations indicative for embryonic developmental disorders such as craniofacial dysmorphisms could be detected; family history on this issue was unremarkable as well.

On the clinical tentative diagnosis of bilateral preauricular sinuses, the indication for operative removal was set. Unlike the customary recommendations from medical literature, we did not excise the lesions with an ellipse of surrounding skin, but chose a surgical access via a shortened pretragal facelift-incision (Figure 2(a)). By doing so, we had the advantage of a superior exposure of the operation site (Figure 2(b)), combined with the possibility of a radical removal of the complete system of fistulous tracts along with the entire overlying skin, almost without any visible cosmetic impairment after wound healing. Tension on the sutures could be avoided by mobilisation of the superficial musculoaponeurotic system (SMAS) and fixation to Loré's fascia.

The operation, which was carried out under local anaesthesia, was uneventful, as was the postoperative course. Sutures were removed 1 week postoperatively, at this time, the patient was already free of discomfort. 


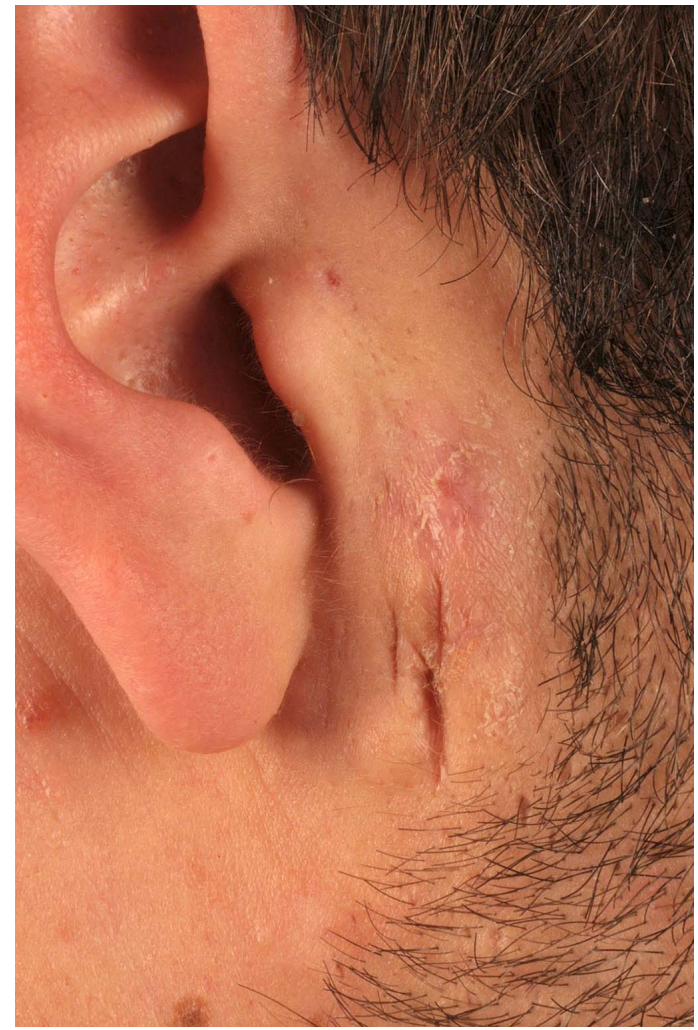

Figure 1. Preoperative view of the preauricular findings.

Histopathologic examination confirmed the in-sano-excision of multiple epidermal cysts with surrounding chronic inflammation.

Until now (1 year postoperatively), there are no signs of recurrence and almost invisible scarring (Figure 3; 3 months postoperatively).

\section{Surgical Approach}

The standard surgical access for facelift procedures is an incision starting in the temporal region parallel to the hairline towards the upper pole of the concha, then threefold convexly curved preauricularly proximate to the crus of the helix, the tragus and the earlobe, caudally encircling the earlobe and ascending retroauricularly to the superior aspect of the conchal bowl, then curving into the scalp dorsally [1]. Especially in males, a retrotragal incision should be avoided due to the risk of distorsion of the hair-bearing skin onto the tragus. For the indication presented here, we solely used the periauricular part of the incision (Figures 2(a) and (b)).

After premedication with $7.5 \mathrm{mg}$ Midazolame p.o. and instillation of local anaesthesia (Mepivacain 1\% with Epinephrine 1:50,000; $3 \mathrm{ml}$ per side), preparation was carried out superficial to the capsula of the parotid gland with mobilisation of the skin and the SMAS $3 \mathrm{~cm}$ rostrally (similar to a mini-Facelift-procedure). Having com-

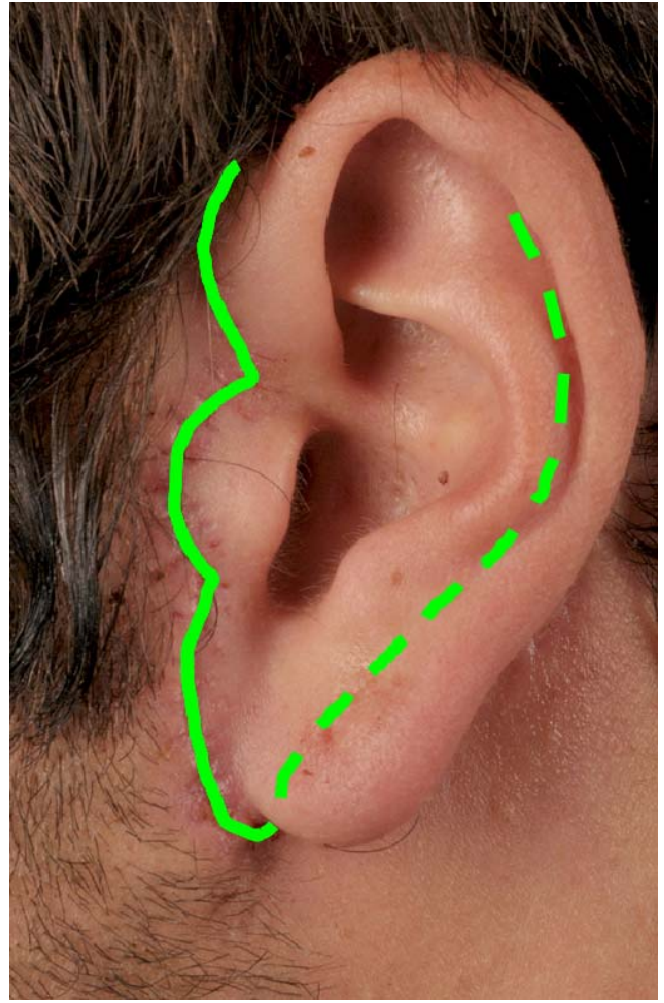

(a)

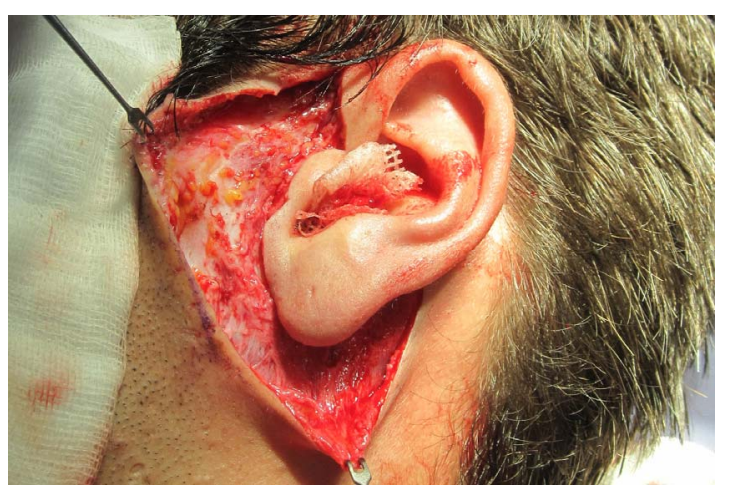

(b)

Figure 2. (a) Visualization of the face lift incision line; (b) Intraoperative view with excellent exposure of the whole periauricular area.

plete exposure of the periauricular area, en-bloc-removal of the fistulae-bearing tissue could be achieved by a U-shaped excision, removal of cartilage was not necessary in this case.

Due to the extended tissue mobilisation and underlying fixation of the SMAS to Loré's fascia (tympanoparotid fascia), skin closure could be achieved free of tension, there was no need for inserting a drainage.

\section{Discussion}

Preauricular sinuses, cysts or fistulae occur during auri- 


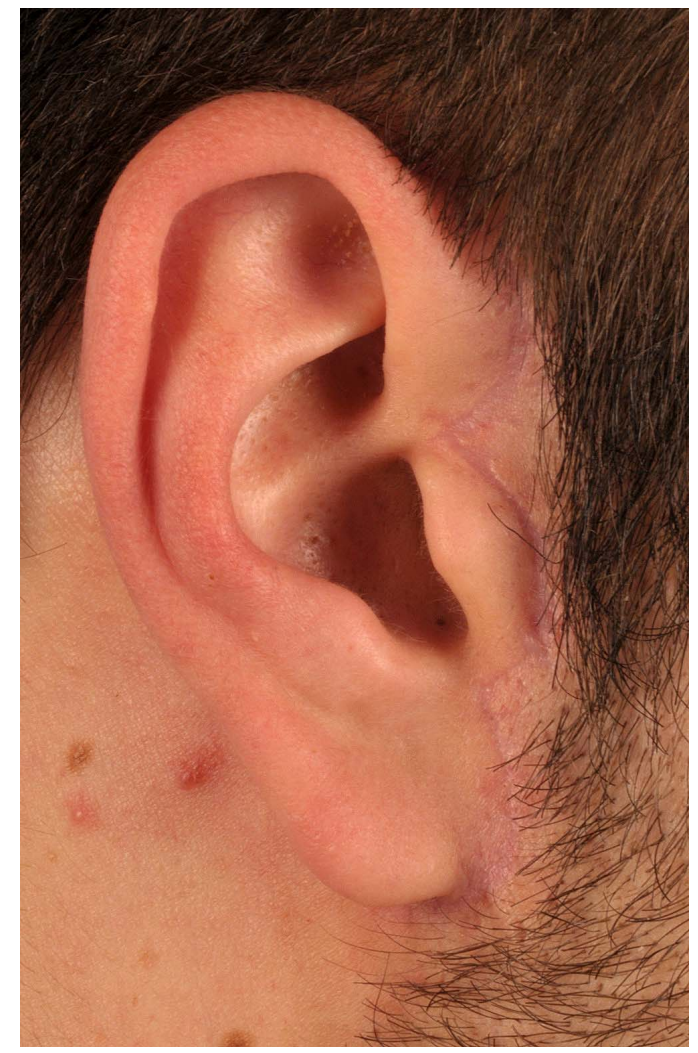

Figure 3. Situation 3 months postoperatively.

cular development due to a defective or incomplete fusion of the auricular hillocks, they can be either inherited or sporadic $[2,3]$. They are often asymptomatic, but recurrent infections require an operative removal. In case of incomplete excision, recurrence is likely; literature presents recurrence rates of up to $42 \%$ [3-5].

Several methods have been described to lower the recurrence rate by improving the indentification of the cystic ducts, i.e. insertion of a probe or instillation of Methylene blue [5,6], expanding the area of resection $[4,7,8]$ or even interposition of the temporoparietal fascia [9].

To further improve the treatment of this benign, but difficult to eradicate malformation, we suggest the surgical approach shown here. As a consequence of the course of the incision line similar to a facelift procedure, it allows a far more radical excision with only minimal aesthetic impairment using a shortened facelift-incision and SMAS-fixation.

By leaving behind the arbitrary discrimination of surgical techniques into "aesthetic" and "reconstructive" categories, we were able to provide innovative solutions to various surgical problems:

In a case of basal cell carcinoma in the upper forehead area $2 \mathrm{~cm}$ below the hair line, the excision was performed as a one-stage procedure with radical tumour excision and defect closure using a coronal brow lift.
Thus an optimal placement of the scar could be achieved, along with treating the accompanying eyebrow ptosis as a positive "side effect" [10].

In another case, we combined a sternal defect coverage using a pectoralis major myocutaneous flap with a simultaneous breast reduction; again a favourable aesthetic and functional outcome could be achieved [11].

\section{Conclusion}

The technique shown that there is another example emphasizing on ablative procedures, especially in the face, should always take the options of aesthetic reconstructive surgery into consideration.

\section{Acknowledgements}

The article processing charge was funded by the German Research Foundation (DFG) and the Albert Ludwigs University Freiburg in the funding programme Open Access Publishing.

\section{REFERENCES}

[1] B. F. Connell, "Eyebrow, Face, and Neck Lifts for Males," Clinics in Plastic Surgery, Vol. 5, No. 1, 1978, pp. 15-28.

[2] C. F. Heusinger, "Hals-Kiemen-Fisteln von Noch Nicht Beobachteter Form,” Archiv für Pathologische Anatomie und Physiologie und für klinische Medicin, Vol. 29, No. 3-4, 1864, pp. 358-365. doi:10.1007/BF01937182

[3] T. Tan, H. Constantinides and T. E. Mitchell, "The Preauricular Sinus: A Review of Its Aetiology, Clinical Presentation and Management," International Journal of Pediatric Otorhinolaryngology, Vol. 69, No. 11, 2005, pp. 1469-1474. doi:10.1016/j.ijporl.2005.07.008

[4] S. Prasad, K. Grundfast and G. Milmoe, "Management of Congenital Preauricular Pit and Sinus Tract in Children," Laryngoscope, Vol. 100, No. 3, 1990, pp. 320-321. doi:10.1288/00005537-199003000-00021

[5] E. Gur, A. Yeung, M. Al-Azzawi and H. Thomson, "The Excised Preauricular Sinus in 14 Years of Experience: Is There a Problem?” Plastic \& Reconstructive Surgery, Vol. 102, No. 5, 1998, pp. 1405-1408. doi:10.1097/00006534-199810000-00012

[6] R. G. Chami and J. Apesos, “Treatment of Asymptomatic Preauricular Sinuses: Challenging Conventional Wisdom,” Annals of Plastic Surgery, Vol. 23, No. 5, 1989, pp. 406-411. doi:10.1097/00000637-198911000-00005

[7] R. J. B. de Jong, "A New Surgical Technique for Treatment of Preauricular Sinus,” Surgery, Vol. 137, No. 5, 2005, pp. 567-570. doi:10.1016/j.surg.2005.01.009

[8] H. C. Lam, G. Soo, P. J. Wormald and C. A. Van Hasselt, "Excision of the Preauricular Sinus: A Comparison of Two Surgical Techniques,” Laryngoscope, Vol. 111, No. 2, 2001, pp. 317-319. doi:10.1097/00005537-200102000-00024 
[9] C. I. Wu, C. C. Chen and S. C. Chang, "Treatment of Recurrent Intractable Periauricular Fistula Using Temporoparietal Fascia," Journal of Craniofacial Surgery, Vol. 21, No. 4, 2010, pp. 1224-1225.

doi:10.1097/SCS.0b013e3181e17b66

[10] N. Torio-Padron, H. Bannasch, S. U. Eisenhardt, A. S. Dowlatshahi and G. B. Stark, "Surgical Treatment of a Basal Cell Carcinoma in the Upper Forehead Area by Combination of Reconstructive and Aesthetic Surgical
Techniques,” Journal of Plastic, Reconstructive \& Aesthetic Surgery, Vol. 63, No. 2, 2010, pp. e151-e152. doi:10.1016/j.bjps.2009.05.048

[11] N. Iblher, V. Penna, S. Krischak and G. B. Stark, "Simultaneous Pectoralis Major Myocutaneous Flap Combined with Breast Reduction for Sternal Defect Coverage," Journal of Plastic, Reconstructive \& Aesthetic Surgery, Vol. 62, No. 8, 2009, pp. 1076-1080.

doi:10.1016/j.bjps.2008.04.023 